Rev. Elet. em Gestão, Educação e Tecnologia Ambiental (e-ISSN: 2236-1170)

\title{
SEPARAÇÃO DE MATERIAIS RECICLÁVEIS: PANORAMA NO BRASIL E INCENTIVOS À PRÁTICA
}

\author{
Ana Cláudia Ribeiro Rossi Neves ${ }^{1}$, Luiz Otávio de Almeida Castro ${ }^{2}$ \\ ${ }^{1}$ Engenheira Agrônoma. Mestre em Ciência e Tecnologia pela Escola Superior de Agricultura Luiz de Queiroz, \\ Universidade de São Paulo (ESALQ/USP). Pós-Graduanda em Controle e Gestão Ambiental na Universidade Santa \\ Cecília de Santos., anaclrossi@yahoo.com.br \\ 2 Engenheiro Civil. Mestre em Saúde Pública pela Universidade de São Paulo (FSP/USP). Especialista em Controle e \\ Gestão Ambiental pela Universidade Santa Cecília de Santos. Professor de pós-graduação na Universidade Santa \\ Cecília de Santos. loac73@bignet.com.br
}

http://dx.doi.org/10.5902/223611706631

\section{RESUMO}

Um dos desafios gerados pela Política Nacional de Resíduos Sólidos, que entrou em vigor no Brasil em agosto 2010, é a adesão dos municípios à coleta seletiva dos resíduos. Dados de instituições governamentais e de pesquisa científica têm mostrado que milhões de toneladas de resíduos sólidos urbanos por ano ainda têm destino impróprio no país e apenas $14 \%$ dos municípios operam programas estruturados de coleta seletiva. Mesmo em cidades que contam com programas de coleta seletiva, a quantidade de materiais recicláveis desprezados ainda é grande e a baixa participação da população na separação de materiais contribui para este cenário. O presente estudo tem como objetivos retratar a situação da separação e coleta de materiais recicláveis no Brasil e apresentar resultados de estudos que identificaram fatores que motivam as práticas de separação e as barreiras em vários países.

Palavras-chave: separação de materiais recicláveis; coleta seletiva; fatores motivadores e barreiras.

\section{ABSTRACT}

One of the challenges generated by the Brazilian Solid Waste Policy, which entered into force in Brazil in August 2010, is the adherence to the selective collection of municipal waste. Data from government institutions and scientific research have shown that millions of tons of municipal solid waste per year still have improper destination in the country and only $14 \%$ of cities operate structured selective collection of recyclable material programs. Even in cities that rely on selective waste collection programs, the amount of recyclable materials despised is still great and the low participation of the population in the separation of materials contributes to this scenario. The present study aims to portray the situation of separation and collection of recyclable materials in Brazil and present the results of studies that identified factors that motivate the practices of separation and the barriers in several countries.

Keywords: recyclable materials separation; selective collection of recyclable material; motivational factors and barriers. 
Rev. Elet. em Gestão, Educação e Tecnologia Ambiental (e-ISSN: 2236-1170)

\section{INTRODUÇÃO}

O manejo dos resíduos sólidos produzidos nas áreas urbanas é considerado um dos grandes desafios enfrentados hoje pelas administrações públicas das cidades brasileiras. Os resíduos sólidos urbanos (RSU) são constituídos de resíduos domiciliares, comerciais e resíduos de limpeza urbana, como varrição, limpeza de logradouros e vias públicas. O aumento da geração destes resíduos está relacionado com o aumento da população em geral e também com os hábitos modernos de consumo excessivo, a grande disponibilidade de produtos industrializados acondicionados em embalagens e redução da vida útil dos produtos. Em 2011, apenas 58,1\% do total dos RSU coletados seguiu para aterros sanitários e cerca de 75 mil toneladas diárias ainda tem destinação inadequada, sendo encaminhadas para lixões ou aterros controlados, desprovidos de sistemas necessários para proteção do meio ambiente (ASSOCIAÇÃO BRASILEIRA DE EMPRESAS DE LIMPEZA PÚBLICA E RESÍDUOS ESPECIAIS ABRELPE, 2011; BRASIL, 2010). A destinação inadequada de resíduos, além de gerar graves problemas sociais e de saúde publica, tem grande impacto ambiental, com contaminação do solo e fontes de água superficiais e subterrâneas. Neste cenário, programas de coleta seletiva e reciclagem surgem como alternativas viáveis para a economia de espaços em aterros, limpeza das cidades e preservação ambiental. O presente estudo tem como objetivos retratar a situação da separação e coleta de materiais recicláveis no Brasil e apresentar resultados de estudos que identificaram fatores que motivam as práticas de separação e as barreiras em vários países.

\section{SEPARAÇÃO E COLETA DE MATERIAIS RECICLÁVEIS NO BRASIL}

Após cerca de 20 anos de discussões, em agosto 2010 entrou em vigor no Brasil a Lei no 12.305 que instituiu a Política Nacional de Resíduos Sólidos (PNRS). A chegada desta lei no ordenamento jurídico brasileiro, e sua integração à Política Nacional de Meio Ambiente e à Política de Saneamento Básico, completou o arcabouço regulatório necessário para propiciar o desenvolvimento da gestão de resíduos no Brasil e implicou em mudanças nos sistemas adotados (ABRELPE, 2010). A PNRS reconhece o resíduo sólido reutilizável e reciclável como um bem econômico, de valor social, gerador de trabalho, renda e promotor de cidadania. Também institui a coleta seletiva como instrumento de gestão sustentável. A elaboração de Planos Municipais de Gestão Integrada de Resíduos Sólidos é condição para os municípios terem acesso aos recursos da União destinados à limpeza urbana e ao manejo de resíduos sólidos, ou para receberem incentivos e financiamentos de entidades federais de crédito ou fomento para tal finalidade, após agosto de 2012. As metas de redução, reutilização, coleta seletiva e reciclagem de resíduos devem ser contempladas nos planos municipais (BRASIL, 2010).

De acordo com dados da Associação Brasileira de Empresas de Limpeza Pública e Resíduos Especiais - ABRELPE (2011), o total de RSU gerado no país em 2011 foi de aproximadamente 61,9 milhões de toneladas, o que significou uma geração per capita de 381,6 quilogramas. O total de RSU coletado no mesmo ano foi de aproximadamente 55,5 milhões de toneladas. Sendo assim, em torno de 6,4 milhões de toneladas de RSU deixaram de ser coletadas em 2011 e provavelmente tiveram destino impróprio. 
Rev. Elet. em Gestão, Educação e Tecnologia Ambiental (e-ISSN: 2236-1170)

Em 2011, dos 5.565 municípios brasileiros, 3.263 (58,6\%) indicaram a existência de iniciativas de coleta seletiva, sendo que $40,9 \%$ destes estão localizados na região sudeste e $28,6 \%$ na região sul. Em seguida aparece o Nordeste, com 19,9\% dos municípios com iniciativas de coleta seletiva no Brasil, o Norte, com $6,4 \%$ e o Centro-Oeste, com 4,0\%. No entanto é importante considerar que muitas vezes tais iniciativas resumem-se na disponibilização de pontos de entrega voluntária à população ou na formalização de convênios com cooperativas de catadores para a realização dos serviços (ABRELPE, 2011). De acordo com dados da pesquisa da associação Compromisso Empresarial para Reciclagem - CEMPRE, em 2010, apenas 443 municípios brasileiros contavam com programas de coleta seletiva estruturados, cerca de $8 \%$ do total, sendo que na maior parte deles a coleta não cobria mais que 10\% da população local. Já os dados de 2012 demonstram que 766 municípios contam com o serviço estruturado, cerca de $14 \%$ do total, sendo que 401 estão localizados na região sudeste e 257 na região sul. A grande maioria das cidades (88\%) realiza coleta de porta em porta, $53 \%$ tem postos de entrega voluntária como alternativa e $72 \%$ trabalham com cooperativas de catadores para complementar os serviços. Os programas com maior êxito são aqueles que utilizam combinação dos diferentes modelos (CEMPRE, 2012).

Santos (SP), Santo André (SP), São Jose dos Campos (SP), São Bernardo do Campo (SP), Curitiba (PR), Londrina (PR), Florianópolis (SC), Itabira (MG), Porto Alegre (RS) e Goiânia (GO) estão entre as cidades brasileiras com maior porcentagem de população atendida pela coleta seletiva (CEMPRE, 2010; 2012). No entanto, mesmo em algumas destas cidades, que oferecem a coleta de materiais recicláveis de porta em porta, o percentual de recicláveis recuperado é baixo, em parte devido à baixa taxa de separação de materiais pela população. Em Curitiba (PR), por exemplo, houve um aumento de $192 \%$ na quantidade de materiais recicláveis coletados no ano de 2009 em comparação ao ano de 2005. No ano de 2009 o município coletou 437.904 toneladas de lixo com a coleta convencional porta em porta, enquanto a quantidade de materiais recicláveis coletados com o mesmo sistema foi de 22.420 toneladas, ou seja, em torno de $5 \%$ da coleta tradicional. Em Santos (SP), que também oferece a coleta seletiva porta em porta, houve um aumento de $260 \%$ na quantidade de resíduos recicláveis coletados no ano de 2011 em comparação a 2005 e o percentual de recicláveis recuperado corresponde a aproximadamente $2 \%$ do total destinado ao aterro. Em São Bernardo do Campo (SP) o Programa de Coleta Seletiva implantado no município desde 2000 atende 1,2\% dos resíduos gerados no município (CURITIBA, 2010; SÃO BERNADO DO CAMPO, 2010; SANTOS, 2012). De acordo com a Composição Gravimétrica dos RSU no Brasil apresentada pela ABRELPE (2011), a quantidade de resíduos recicláveis pode chegar a 31,9\% do total, sendo o restante composto por matéria orgânica $(51,4 \%)$ e outros materiais $(16,7 \%)$. Aparas de papel e papelão continuam sendo os tipos de materiais recicláveis mais coletados pelos sistemas municipais brasileiros de coleta seletiva. Em seguida aparecem os plásticos em geral, vidros, metais e embalagens longa vida. No entanto a porcentagem de rejeito na composição gravimétrica da coleta seletiva é grande, sendo 13,3\% em 2010. Em 2012, esta porcentagem aumentou para 17,4\%, demonstrando que é preciso melhorar os serviços de coleta e a conscientização da população para separação correta dos resíduos (CEMPRE, 2010; 2012).

Alguns trabalhos realizados em cidades brasileiras, com análise da composição gravimétrica de RSU em seus destinos finais, demonstram os padrões de comprometimento da população com os programas de coleta seletiva. Em Itaúna (MG), a coleta seletiva é diária e recolhe resíduos secos, como plásticos e metais e resíduos molhados, como sobras de alimentos e papel higiênico em dias alternados. De acordo com estudo realizado em 2012, na coleta de resíduos molhados, os materiais recicláveis somaram $18 \%$ do total coletado. Foram encontrados principalmente plásticos e papel, sendo que estes dificultam a decomposição dos resíduos e 
Rev. Elet. em Gestão, Educação e Tecnologia Ambiental (e-ISSN: 2236-1170)

reduzem a área de disposição dos aterros, além de não participarem do processo de reciclagem. $\mathrm{Na}$ verificação da composição dos resíduos secos coletados foi constatado que a quantidade de materiais não recicláveis, como matéria orgânica, representou 44\% do total (COLETA, 2012; MOURA; LIMA; ARCHANJO, 2012).

Um estudo conduzido em Lajeado (RS) caracterizou os resíduos sólidos domésticos descartados por meio de coleta regular e seletiva em diferentes bairros do município. Foi verificado que os materiais recicláveis constituíam apenas $51 \%$ do total de resíduos na coleta seletiva, sendo o restante composto por papel higiênico, fraldas e material orgânico. Na coleta convencional os recicláveis somaram $28 \%$ do total coletado (KONRAD; CASARIL; SCHMITZ, 2010).

Em São Carlos (SP) foi realizada a caracterização física dos resíduos sólidos domiciliares em aterro sanitário e em três centrais de triagem. No aterro, $59,08 \%$ do total era composto por matéria orgânica e $20,83 \%$ eram resíduos recicláveis, como plásticos, papel e papelão, vidro, metal e alumínio e embalagem cartonada. Já nas centrais de triagem, $47,41 \%$ correspondia a papel e papelão, $21,60 \%$ a plásticos, $12,25 \%$ a vidros, 7,63\% a metal e alumínio, 5,30\% a embalagem cartonada; e 5,79\% a rejeitos (FRÉSCA; PUGLIESI; MASSUKADO; SCHALCH, 2008).

Em Passo Fundo (RS) foi estudada a composição gravimétrica de materiais aterrados em um lixão e em um aterro controlado. Os resultados obtidos demonstraram que cerca de $52,7 \%$ dos materiais aterrados eram recicláveis. No lixão, o principal componente identificado na composição gravimétrica dos resíduos sólidos foi o plástico filme, representado principalmente por sacolas de supermercados utilizadas para acondicionar restos de alimentos (MATTEl; ESCOSTEGUY, 2007).

Dados divulgados pelo Instituto Brasileiro de Opinião Pública e Estatística - IBOPE, em 2012, mostram que $86 \%$ da população brasileira concordam que a separação de materiais recicláveis é um dever de todos, porém apenas $26 \%$ declararam que separam os materiais sempre ou frequentemente. A pesquisa ainda mostra que as pessoas com idade entre 35 e 75 anos separam mais materiais recicláveis. As mais jovens, na faixa dos 20 aos 24 anos, reutilizam mais materiais. Para essa pesquisa, foram ouvidas 10.368 pessoas entre julho de 2011 e fevereiro de 2012 (BIBLIOTECA VIRTUAL DO GOVERNO DO ESTADO DE SÃO PAULO, 2012). De acordo com a Pesquisa de Orçamentos Familiares 2008-2009 do Instituto Brasileiro de Geografia e Estatística (IBGE), na Região Sul, 59,9\% dos domicílios separam material biodegradável do não biodegradável, enquanto na Região Norte, que tem apenas 14 municípios com serviços estruturados de coleta seletiva, 6,6\% dos domicílios realizam a separação (ABDALA, 2012; CEMPRE, 2012).

\section{FATORES MOTIVADORES E BARREIRAS À PRÁTICA DE SEPARAÇÃO DE MATERIAIS RECICLÁVEIS}

O entendimento dos fatores que motivam e dos fatores que desmotivam (barreiras) as pessoas a realizar a separação do material reciclável do restante dos resíduos é o primeiro passo para o aumento da participação em programas de coleta seletiva (ACETI ASSOCIATES, 2002). Campanhas eficazes sobre reciclagem fazem com que as pessoas comecem a participar e continuem participando. Quando a separação de materiais é voluntária, os programas de coleta seletiva, para serem eficientes, devem prover as pessoas com razões ou motivos que cativem a participação. E estes motivos devem ter efeito duradouro para sustentar o interesse da população através do tempo (MORGAN; HUGHES, 2006). 
Rev. Elet. em Gestão, Educação e Tecnologia Ambiental (e-ISSN: 2236-1170)

Diversos estudos foram conduzidos com a intenção de identificar as motivações e barreiras associadas com o comportamento das pessoas em relação à separação de materiais para a reciclagem. Na identificação de fatores que influenciam a participação das pessoas é importante observar padrões que surgem de resultados de diversos estudos, nos quais os pesquisadores geralmente entrevistam voluntários que tem ou não o hábito de separar materiais e avaliam a significância dos resultados (ACETI ASSOCIATES, 2002). Os dados obtidos podem ser utilizados na elaboração de campanhas, aumentando a participação da população nos programas de reciclagem, com consequente economia de recursos financeiros e melhoria da qualidade de vida das cidades em diversos aspectos.

Um documento elaborado por uma empresa de consultoria norte-americana, baseado em diversas pesquisas sobre o tema, identificou as seguintes motivações para a participação das pessoas na separação de materiais: economia de espaços em aterros, melhora da qualidade ambiental, preocupação com meio ambiente, pressão social e incentivos monetários. Entre as barreiras estavam: falta de tempo para a separação de materiais, falta de conhecimento sobre o que separar ou como separar, limitação do espaço para armazenagem e falta de postos de entrega para materiais recicláveis (ACETI ASSOCIATES, 2002). Omran et al. (2011) aplicaram 275 questionários em Pulau Penang na Malásia e a pesquisa mostrou que $61 \%$ das pessoas entrevistadas participavam do programa de reciclagem municipal. Limpeza do ambiente, manutenção de condições de saúde, conservação dos recursos naturais para as futuras gerações e economia de espaços em aterros estavam entre as principais motivações para separação de resíduos. Entre as principais barreiras identificadas estavam a distância excessiva de centros de entrega voluntária e a falta de tempo.

Várias pesquisas indicam a preocupação ambiental como principal motivação para participar de práticas relacionadas com a reciclagem. Em pesquisa realizada por Vining e Ebreo, em 1990, com 197 residentes de Illinois, nos Estados Unidos, a preocupação com o meio ambiente foi citada como fator motivador tanto por pessoas que praticavam a separação de materiais, como por pessoas que não praticavam. No entanto, segundo os pesquisadores, os entrevistados que não separavam davam mais importância a incentivos financeiros, brindes e conveniência pessoal do que as pessoas que separavam materiais. Na pesquisa conduzida por Omran et al. (2009), as principais motivações para participação de residentes em uma cidade localizada no norte da Malásia foram a economia de espaços nos aterros e conservação dos recursos naturais para as futuras gerações. Quanto às barreiras, as principais citadas foram a falta de tempo e a distância das instalações. Em estudo realizado no Estado de Perak, na Malásia, com 347 residentes, $71 \%$ dos entrevistados estavam envolvidos em práticas de separação de materiais e os principais motivos apresentados foram a preocupação com o meio ambiente e com falta de espaços nos aterros, além de incentivos recebidos por parte dos filhos. Entre os entrevistados que disseram não praticar a separação, os principais motivos citados foram a falta e a inadequação das instalações. Alguns entrevistados afirmaram não ver importância na prática (OMRAN; GEBRIL, 2011). Também em Illinois, nos Estados Unidos, uma pesquisa realizada com quatro comunidades mostrou que entre os motivos que levam as pessoas a participar dos programas de reciclagem, a conservação de recursos naturais foi o único motivo citado por todas, sendo considerado o mais importante (VINING; LINN; BURDGE, 1992). De acordo com os autores, os resultados demonstram que programas de reciclagem voluntária, que oferecem conveniência para as pessoas e que têm base na preocupação com o meio ambiente são meios muito úteis de reduzir os resíduos. Meen-Chee e Narayanan (2006), em sua pesquisa realizada na Malásia, também relacionaram a preocupação com o meio ambiente com o aumento na participação da separação de recicláveis. 
Rev. Elet. em Gestão, Educação e Tecnologia Ambiental (e-ISSN: 2236-1170)

Incentivos monetários também são eficazes para aumentar a participação das pessoas em programas de reciclagem. Algumas cidades pelo mundo adotam programas pay-as-you-throw PAYT ("pague pelo que joga fora", em inglês), nos quais os munícipes são cobrados pela coleta convencional de resíduos sólidos com base na quantidade de resíduos descartados, o que gera um incentivo econômico direto para aumentar a separação do material reciclável e diminuir a geração de resíduos. De acordo com a Agência de Proteção Ambiental dos Estados Unidos (Environmental Protection Agency - EPA) comunidades que adotaram este sistema têm reportado aumentos significativos na separação de materiais recicláveis.

Um estudo comparou três estratégias utilizadas nos Estados Unidos para incentivar a separação de material reciclável: Recycling Credits, RecycleBank e PAYT. O Recycling Credits, programa de obtenção de créditos com a troca de materiais recicláveis, provê o munícipe com incentivos pela participação no programa de reciclagem, como descontos na conta de lixo. 0 Recycle Bank funciona como uma espécie de banco no qual os munícipes recebem pontos em troca de materiais recicláveis entregues em um posto, que podem ser trocados por descontos ou brindes em compras realizadas em diversas lojas onde os comerciantes são parceiros do programa. De acordo com a pesquisa, o sistema PAYT, utilizado em mais de 7100 comunidades nos Estados Unidos, reduziu a geração de lixo residencial em torno de $17 \%$, sendo que aproximadamente um terço desta redução deveu-se ao aumento da separação de materiais para reciclagem. No sistema Recycle Bank foram encontrados em algumas comunidades aumento na taxa de separação em até 30\% (SKUMATZ et al., 2011). Outros dados mostram que é possível uma redução entre $14 \%$ e $27 \%$ dos resíduos gerados na fonte, com aumento de taxa de coleta de materiais recicláveis de $32 \%$ a 59\% com o sistema PAYT (MIRANDA; LAPALME, 1997).

No Brasil, iniciativas que envolvem incentivos já foram implantadas em algumas cidades. O programa Feira Verde, da Prefeitura de Ponta Grossa (PR), tem por finalidade realizar a troca de material reciclável levado pelos cidadãos por frutas, legumes e verduras adquiridos junto aos agricultores familiares. Desde sua implantação em 2007 já coletou cerca 8,4 mil toneladas de resíduos recicláveis e por mês o programa distribui alimentos para aproximadamente 20 mil famílias. No programa Câmbio Verde, da Prefeitura de Curitiba (PR), a cada quatro quilos de material reciclável entregue, o participante recebe um quilo de hortifrúti. Com a iniciativa são coletadas aproximadamente 310 toneladas de resíduos recicláveis por mês. Em Campos dos Goytacazes (RJ) em troca da entrega de material reciclável em postos específicos, os moradores levam adubo orgânico feito da compostagem de folhas, terra, areia e restos de alimentos. Em Embu das Artes (SP), o munícipe pode trocar o material reciclável por mudas indicadas pelo Viveiro Municipal. O Projeto Vale Luz, na Bahia, realiza a troca de resíduos sólidos recicláveis por descontos na conta de energia (ANTUNES, 2011; CURITIBA, 2010; PEV, 2012; FERREIRA, 2011; MATERIAL, 2012).

\section{CONCLUSÕES}

Após dois anos da aprovação da Política Nacional dos Resíduos Sólidos houve um incremento no número de cidades brasileiras com programas consolidados de coleta seletiva. No entanto, mesmo em municípios onde grande parte da população é atendida pelo serviço, a quantidade de materiais recicláveis coletados ainda é baixa, sendo parte do total coletado composta por rejeitos. Quando a separação de materiais não é realizada de forma correta, além 
Rev. Elet. em Gestão, Educação e Tecnologia Ambiental (e-ISSN: 2236-1170)

do encarecimento do processo de triagem, muitos materiais passíveis de reciclagem são inutilizados.

Estes fatos demonstram a baixa adesão das pessoas aos programas de coleta seletiva e ressaltam a necessidade de programas educativos abordando a importância da reciclagem de materiais e a forma correta de separação dos mesmos.

A participação da população é fundamental para o sucesso de qualquer programa de coleta seletiva. $O$ entendimento dos fatores que motivam e desmotivam as pessoas a realizar a separação de material reciclável em determinada região é de grande importância para o aumento da participação da comunidade. Cada região deve identificar suas barreiras e removê-las, assim como identificar o que motiva a população local quando se trata de separar os materiais recicláveis. De acordo com a literatura estudada, uma grande barreira para a participação popular em diversas localidades é a falta de estrutura adequada. No entanto, quando há estrutura adequada, é importante identificar fatores que motivem o uso das instalações existentes. Estes dados devem ser utilizados para a elaboração de campanhas de educação ambiental.

Existe grande quantidade de matéria orgânica presente nos RSU coletados no Brasil. Este fato chama a atenção para a necessidade de redução de desperdício de alimentos pelos consumidores finais, reduzindo assim a quantidade de resíduos em aterros. A matéria orgânica que compõe os RSU das cidades também pode ser aproveitada, através da compostagem e utilizada como adubo, dentre outros sistemas disponíveis.

Além da importância ambiental da separação de materiais recicláveis, as práticas de reciclagem em geral também têm grande importância social, como geradoras de emprego e renda para catadores. A população deve ser informada deste aspecto, inclusive como fator motivador para o aumento da participação em programas de coleta seletiva.

Finalizando, programas de coleta seletiva que ofereçam infra-estrutura adequada, implantados com participação de catadores, e aliados a campanhas de educação baseadas em fatores que motivam a separação de materiais identificados na população local, têm grande chance de obterem êxito e são importantes ferramentas para se atingir a sustentabilidade nas cidades.

\section{REFERÊNCIAS BIBLIOGRÁFICAS}

ABDALA, V. Grande parte do lixo separado não é coletada seletivamente. Exame.com, Rio de Janeiro, 14 set. 2012. Disponível em: < http://www.exame.abril.com.br >. Acesso em: 20 set. 2012.

ACETI ASSOCIATES. Recycling: Why People Participate; Why They Don't, A Barrier/Motivation Inventory: The Basis of Community-Based Social Marketing. Arlington, 2002. 4p.

ANTUNES, P. Feira Verde - Programa garante variedade de alimentos na mesa de milhares de famílias. Site da Prefeitura Municipal de Ponta Grossa - PR, Ponta Grossa, 31 jan. 2011. Disponível em: < http://www.pontagrossa.pr.gov.br/node >. Acesso em: 24 jul. 2012.

ASSOCIACAO BRASILEIRA DE EMPRESAS DE LIMPEZA PUBLICA E RESIDUOS ESPECIAIS - ABRELPE. Panorama dos Resíduos Sólidos no Brasil 2010. São Paulo, 2010. 202p. Disponível em: < http://www.abrelpe.org.br >. Acesso em: 10 jun. 2012. 
Rev. Elet. em Gestão, Educação e Tecnologia Ambiental (e-ISSN: 2236-1170)

. Panorama dos Resíduos Sólidos no Brasil 2011. São Paulo, 2011. 186p. Disponível em:

< http://www.abrelpe.org.br >. Acesso em: 10 jun. 2012.

BRASIL. Lei n. 12305, de 2 de agosto de 2010. Institui a Política Nacional de Resíduos Sólidos e dá outras providências. Disponível em: < http://www.planalto.gov.br >. Acesso em: 03 jul. 2012.

COLETA seletiva de resíduos - uma ação em prol do meio ambiente. Site da Prefeitura Municipal de Itaúna - MG, Itaúna, 23 jul. 2012. Disponível em:

< http://www.itauna.mg.gov.br/mat vis.aspx?cd=11192 >. Acesso em: 01 ago. 2012.

COMPROMISSO EMPRESARIAL PARA RECICLAGEM - CEMPRE. Cresce o número de cidades do Brasil que realizam a coleta seletiva. São Paulo. São Paulo, 2012. Disponível em:

< http://www.cempre.org.br/imprensa.php >. Acesso em: 10 set. 2012.

.Pesquisa CICLOSOFT 2010. São Paulo, 2010. Disponível em:

http://www.cempre.org.br >. Acesso em: 16 ago. 2012.

CURITIBA. Secretaria Municipal do Meio Ambiente. Plano De Gestão Integrada De Resíduos Sólidos de Curitiba. Curitiba: Prefeitura Municipal De Curitiba, 2010. 121p. Disponível em:

< http://www.curitiba.pr.gov.br >. Acesso em: 02 set. 2012.

ESTADOS UNIDOS. Environmental Protection Agency - EPA. Conservation Tools - Pay-As-You-Throw. Washington DC, 2012.

Disponível em: < http://www.epa.gov/osw/conserve/tools/payt >. Acesso em: 03 ago. 2012.

FERREIRA, T. Serviços Públicos inaugura mais um posto de troca de recicláveis. Site da Prefeitura Municipal de Campos dos Goytacazes - RJ, Campos dos Goytacazes, 04 ago. 2011. Disponível em: < http://www.campos.ri.gov.br/exibirNoticia.php?id noticia=8757 >. Acesso em: 24 jul. 2012.

FRÉSCA, F. R. C.; PUGLIESI, E.; MASSUKADO, L. M.; SCHALCH, V. Determinação da composição gravimétrica dos resíduos sólidos domiciliares do município de São Carlos-SP. Revista DAE, São Paulo, n. 178, p. 48-57, 2008. Disponível em: < http:// www.revistadae.com.br >. Acesso em: 16 jul. 2012.

KONRAD, O.; CASARIL, C. E.; SCHMITZ, M. Estudo dos resíduos sólidos domésticos de Lajeado/RS pela caracterização gravimétrica. Revista Destaques Acadêmicos - UNIVATES, Lajeado, ano 2, n. 4, p. 57-62, 2010. Disponível em: < http:// www.univates.br>. Acesso em: 16 maio 2012.

MATERIAL reciclável pode ser trocado por desconto em conta de luz na BA. Portal de notícias da Globo G1 Bahia. Disponível em: < http://g1.globo.com/bahia >. Acesso em: 01 set. 2012

MATTEI, G. E ESCOSTEGUY, P. A. V. Composição gravimétrica de resíduos sólidos aterrados. Engenharia Sanitária e Ambiental, Rio de Janeiro, v.12, n.3, p, 247-251, 2007. Disponível em:

< http://www.scielo.br > Acesso em: 10 ago. 2012.

MEEN-CHEE, H.; NARAYANAN, S. Restoring the Shine to a Pearl: Recycling Behavior in Penang, Malaysia. Development and Change, Oxford, v. 37, n. 5, p. 1117- 1136, 2006. Disponível em: < http://onlinelibrary.wiley.com >. Acesso em: 10 jun. 2012.

MIRANDA, M .L.; LAPALME, S. Unit Pricing of Residential Solid Waste: A Preliminary Analysis of 212 US Communities. Washington DC, 1997. Disponível em:

< http:// www.epa.gov/payt/research.htm >. Acesso em: 19 ago. 2012. 
Rev. Elet. em Gestão, Educação e Tecnologia Ambiental (e-ISSN: 2236-1170)

MORGAN, F. W.; HUGHES, M. V. Understanding Recycling Behavior in Kentucky: Who Recycles and Why. Journal of the Minerals, Metals, and Materials Society, New York, v. 58, n. 8, p. 32-35, 2006. Disponível em: < http:// www.secat.net >. Acesso em: 13 jun. 2012.

MOURA, A. A.; LIMA, W. S. de; ARCHANJO, C. R. Análise da composição gravimétrica de resíduos sólidos urbanos: estudo de caso - município de Itaúna - MG. Synthesis Revista Digital FAPAM, São Geraldo, n.3, p. 4-16, 2012. Disponível em: < http:// www.fapam.edu.br/revista > Acesso em: 13 ago. 2012.

OMRAN, A.; GEBRIL, A. O. Study of household attitude toward recycling of solid wastes: a case study. Acta Technica Corviniensis - Bulletin Of Engineering, Timisoara, v. 4, n. 1, p. 79-82, 2011. Disponível em: < http://acta.fih.upt.ro >. Acesso em: 01 jul. 2012.

OMRAN, A.; MAHMOOD, A.; READ, A.D. A Study oh the motivation and de-motivation factors influencing the participation of people o Pulau Pinang in recycling solid waste. The Journal of Solid Waste Technology and Management, Chester, v. 37, n. 2, p. 91-101, 2011.

OMRAN, A.; MAHMOOD, A.; ABDUL AZIZ, H.; ROBINSON, G.M. Investigating Households Attitude Toward Recycling of Solid Waste in Malaysia: A Case Study. International Journal of Environmental Research, Tehran, v. 3, n. 2, p. 275-288, 2009. Disponível em:

<http:// www.sid.ir >. Acesso em: 21 jul. 2012.

PEV - Ponto de Entrega Voluntária de Material Reciclável. Site da Prefeitura de Embu das Artes. Disponível em: < http://www.embu.sp.gov.br/e-gov/cidade/parque/?ver=1235 >. Acesso em: 03 ago. 2012.

SANTOS. Secretaria Municipal De Meio Ambiente. Plano de Gestão Integrada de Resíduos Sólidos do Município de Santos. Santos: Prefeitura Municipal de Santos, 2012. 147p. Disponível em: <http:// www.santos.sp.gov.br >. Acesso em: 03 set. 2012.

SÃO BERNARDO DO CAMPO. Prefeitura Municipal De São Bernardo Do Campo. Plano Municipal De Resíduos Sólidos Do Município De São Bernardo do Campo. São Bernardo Do Campo: Prefeitura Municipal De São Bernardo Do Campo, 2010. 165p. Disponível em:

< http:// www.saobernardo.sp.gov.br >. Acesso em: 03 set. 2012.

SÃO PAULO (estado). Biblioteca Virtual do Governo do Estado De São Paulo. Recliclagem: especial de junho de 2012. São Paulo, 2012. Disponível em:

< http://www.bibliotecavirtual.sp.gov.br/especial/201206-reciclagem.php >. Acesso em: 03 ago. 2012.

SKUMATZ, L.; FREEMAN, D. J.; D'SOUZA, D.; BEMENT, D. Recycling incentives: part 1. Resource Recycling, Portland, p. 16-21, Feb., 2011. Disponível em: < http://resource-recycling.com/node/1011>. Acesso em: 21 ago. 2012.

VINING, J.; EBREO, A. What Makes a Recycler? A Comparison of Recyclers and Nonrecyclers. Environment and Behavior, Thousand Oaks, v. 22, n. 1, p. 55, 1990. Abstract.

VINING, J.; LINN, N.; BURDGE, R. J. Why Recycle? A comparison of recycling motivations in four communities. Environmental Management, New York, v. 16, n. 6, p.785, 1992. Abstract. 